\section{Edycaçäa

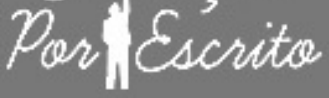

ARTIGO

\title{
A formação continuada e os desafios à (re)construção da profissionalidade
}

\author{
A continuing education and challenges to (re)construction of professionalism
}

José Augusto Florentino ${ }^{\mathrm{a}}$

\section{Editor}

Maria Inês Côrte Vitoria PUCRS, RS, Brasil

\section{Editor Executivo}

Pricila Kohls dos Santos PUCRS, RS, Brasil

\section{Equipe Editorial}

Rosa Maria Rigo PUCRS, RS, Brasil

Carla Spagnolo PUCRS, RS, Brasil Martha Luci Sozo PUCRS, RS, Brasil Dirce Hechler Herbertz PUCRS, RS, Brasil

\section{ISSN 2179-8435}

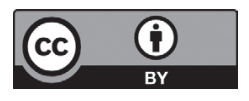

Este artigo está licenciado sob forma de uma licença Creative Commons Atribuição 4.0 Internacional, que permite uso irrestrito, distribuição e reproduçāo
em qualquer meio, desde que a publicaçăo original em qualquer meio, desde
seja corretamente citada.
RESUMO: O presente trabalho tem como objetivo problematizar o tema da formação continuada de professores, tomando como foco o interesse em conhecer mais e melhor os professores e seu trabalho docente, no intuito de descobrir quais caminhos utilizam para ( $r e$ )construir a sua profissionalidade. Nesse sentido, busca-se analisar os processos de formação que auxiliam os professores a responder às demandas, às expectativas, à diversidade e à riqueza de possibilidades dentro e fora da sala de aula. A metodologia utilizada corresponde a uma abordagem qualitativa, descritiva. Para a coleta dos dados utilizou-se como procedimento a observação assistemática da ação docente no cotidiano escolar e entrevista individual com perguntas semiestruturadas. A pesquisa de campo envolveu seis professores de uma instituição de ensino técnico da cidade de Porto Alegre/RS. Os dados foram organizados e interpretados por meio da Análise Textual Discursiva. Os professores indagam e refletem sobre a prática pedagógica, sobre a organização didática de suas aulas, questionando seu papel e a sua responsabilidade no momento de organizar a sua aula, assim como a sua participação sobre o currículo e sobre as decisões no espaço da escola. Os docentes possuem consciência da importância do diálogo, das trocas de experiências; o primeiro passo já foi dado pelos professores ao reconhecerem a necessidade de mudanças; há uma clara percepção por parte deles de que o cenário atual vem exigindo uma (re)construção da profissionalidade do professor e uma (re)adequação do fazer pedagógico para o atendimento das demandas trazidas pelos alunos em sala de aula.

Palavras-chave: formação continuada; prática pedagógica; profissionalidade.

ABSTRACT: This paper aims to discuss the topic of continuing education for teachers, taking as focus the interest in knowing more and better teachers and their teaching in order to find out which paths used to (re)build their professionalism. In that sense, we seek to analyze the formation processes that help teachers respond to the demands, the expectations, the diversity and wealth of possibilities inside and outside the classroom. The methodology used corresponds to a qualitative, descriptive approach. For data collection was used as a procedure to systematic observation of teaching activity in school life and individual interviews with semi-structured questions. The field research involved six teachers from a technical education institution in the city of Porto Alegre/RS. The data were organized and

a Professor da Faculdade Cenecista de Osório. Doutorando do Programa de Pós-Graduação em Educação da PUCRS. 
interpreted through Textual Analysis Discourse. Teachers inquire and reflect on the pedagogical practice on the didactic organization of their classes, questioning its role and its responsibility at the time to organize your class, as well as their participation on the curriculum and on the decisions on the school premises. Teachers have awareness of the importance of dialogue, exchange of experiences; the first step has been taken by teachers to recognize the need for change. There is a clear perception on their part that the present scenario has demanded a (re)construction of the professionalism of the teacher and a (re)adaptation of pedagogical practice to meet the demands brought by students in the classroom.

Keywords: continuing education for teachers; practice pedagogical; professionalism.

\section{Introdução}

estudo que deu origem a este trabalho faz parte da pesquisa de Doutoramento intitulada: "A formação continuada de professores no ensino técnico profissionalizante: a (re)construção da profissionalidade em tempos de paradigma emergente "', no curso de Pós-Graduação em Educação da Pontifícia Universidade Católica do Rio Grande do Sul.

O foco de investigação foi a formação continuada de professores numa visão complexa da ação docente que os auxilie a enfrentar as contingências e a imprevisibilidade nas relações pedagógicas entre professor e alunos. Esta investigação produziu e debruçou-se sobre um tipo particular de textos, ou seja, aqueles através dos quais os próprios professores narram as suas concepções, os seus processos de aprendizagem e as suas experiências vivenciadas e, com isso, dão sentido aos processos de (re)construção da sua profissionalidade.

Parto do pressuposto de que o problema que afeta os professores em sua prática no ensino técnico, sobretudo no que se refere ao ato de aprender e ensinar, na sua complexidade, encontra-se ancorado, possivelmente, na não compreensão, por parte de muitos professores e da própria escola, da necessidade de se trabalhar a formação continuada como um processo coletivo de reflexão e autoformação.

Dessa forma, busco respostas para o problema central desse estudo: Como os professores que atuam no ensino técnico percebem a formação continuada e, consequentemente, os processos de (re)construção da sua profissionalidade em tempos de paradigma emergente?

\footnotetext{
1 Esse paradigma emergente, como descreve Sousa Santos (2009) - entendido do ponto de vista epistemológico como aumento de complexidade
} - está marcado pela perda das certezas, pelo indeterminismo e pela contingência. 


\section{Algumas constatações a partir da prática}

É inegável a insatisfação com a nossa educação no que tange a tentativa de fazer frente à complexa prática pedagógica ${ }^{2}$ - basta olharmos para a nossa própria realidade escolar. Essa insatisfação vem gerando a busca por outro modo de entender os processos de ensino e aprendizagem. Por isso, não seria demasiado exagero dizer que muitas instituições escolares ainda estão preparando nossos alunos para um mundo que já não existe mais, um mundo obsoleto.

Numa sociedade marcada pelo aumento exponencial da informação não podemos aceitar indivíduos que não consigam se adaptar criativamente às mudanças do real. Assim, a grande questão gira em torno da escola e de nós professores, isto é, estamos preparados para encarar e aceitar as mudanças na forma de pensar e fazer Educação?

É possível considerar que, em se tratando da escola em que atuo, muitos professores em sua prática pedagógica parecem não saber como agir e lidar com as contingências da sala de aula.

A relação professor/aluno para ser aprimorada necessita de um profissional aberto a novas possibilidades, ou seja, um professor que traga seu aluno para perto de si, que o compreenda, que o conquiste, que o veja como um ser em (trans)formação. Portanto, é importante que o professor esteja disposto a mudar o seu contexto, uma vez que a maior dificuldade imposta ao professor está no fato de ter que romper ideias, conceitos, crenças, pensamentos, atitudes e preconceitos que estão profundamente arraigadas em seu íntimo e que foram construídas ao longo de sua formação pessoal e profissional, tornando difícil a conscientização e realização dessas rupturas (FREIRE, 1980).

As aulas devem ser um espaço de troca de experiências, de prazer, isto é, um ambiente que fomente a cooperação, o trabalho em equipe, a dinâmica de grupo, o respeito e a afetividade. A tarefa do professor não pode consistir somente em ensinar, em passar conteúdos (muitas vezes descontextualizados da sua realidade) e, sim, definir e planejar situações as quais os alunos possam reformular e construir conhecimentos, atitudes e habilidades a partir da relação experiência e saber (CONTRERAS DOMINGO, 2010).

É preciso, portanto, irritar - no sentido de provocar uma mudança - de corroborar a construção de novos significados a partir da prática. Penso que é necessário haver uma relação mais orgânica entre os saberes da formação

\footnotetext{
2 A docência realizada pelo professor para dar conta do ensino apresenta-se desde logo como uma atividade complexa, pela convergência concomitante de questões teóricas e práticas, com origens no enfrentamento do cotidiano escolar. De certo modo, esta atividade acaba ultrapassando os muros da escola e enfrenta "questões maiores que lhe atribuem um caráter educativo mais amplo do que de simples instrução" (GRILLO, 2002, p. 78).
} 
pedagógica e os saberes construídos na prática, espaço tão importante onde ocorrem os problemas e as dificuldades, onde se experimentam e constroem metodologias e onde se produzem alternativas para contornar os vieses surgidos no cotidiano escolar.

É necessário trabalhar a formação de outro professor, um "profissional capaz de compreender a complexidade e a incerteza de nosso tempo; comprometido com a missão de acompanhar, orientar e estimular o desenvolvimento e a aprendizagem relevante de cada um dos estudantes que estiverem a cargo" (PÉREZ GOMÉZ, 2010, p. 18-19, tradução nossa).

Para tanto, é necessário um processo dinâmico de construções de significados referentes à educação, ao ensino e à aprendizagem, destacando-se nesse processo a importância de uma formação docente que esteja articulada com o paradigma emergente, numa tentativa de entender a complexa realidade do mundo fenomênico e da própria educação.

Nesse sentido, apoiando-me em Ferreira (2010), é possível considerar que o ensino técnico - em tempos de paradigma emergente em que novas demandas e desafios são impostos ao professor constantemente - da forma como está se organizando não dará conta de formar os sujeitos requeridos pelo mundo do trabalho, isto porque ainda é pouco o investimento na organização curricular e na formação dos professores para o trabalho no esino técnico.

\section{A trajetória metodológica}

A Comissão Científica da Faculdade de Educação da Pontifícia Universidade Católica do Rio Grande do Sul analisou e aprovou o projeto por considerá-lo ético e metodologicamente adequado (Número de protocolo: 63/2012). A presente pesquisa correspondeu a um estudo de caso (BECKER, 1997; GOLDIM, 1997; SANTOS, 1999) inserido na abordagem qualitativa (ANDRÉ, 1998; LÜDKE; ANDRÉ, 1986), descritiva. Para a coleta dos dados utilizou-se como procedimento a observação assistemática da ação docente no cotidiano escolar e entrevista individual com perguntas semiestruturadas (MINAYO et al., 1994). Na escolha dos interlocutores foi usado o critério intencional. Participaram da pesquisa seis (6) professores de uma instituição de ensino técnico da cidade de Porto Alegre/RS, sendo dois (2) do curso técnico em Enfermagem, dois (2) do Segurança do Trabalho, um (1) do Meio Ambiente e um (1) da Farmácia. Os professores que participaram da pesquisa assinaram o Termo de Consentimento Livre e Esclarecido, conforme as diretrizes da Resolução no 196, de 10 de outubro de 1996 do Conselho Nacional de Saúde. Aos professores foram dados pseudônimos como forma de manter o anonimato. Os dados foram organizados e interpretados por meio da Análise Textual Discursiva de Moraes (2003). 


\section{Com a palavra os Professores...}

Como recorte, para fins de análise, trago duas categorias: Organização e planejamento da aula frente às contingências da sala de aula, nesta seção as atenções e reflexões estão voltadas para a forma como os professores organizam e planejam suas aulas; Prática pedagógica como processo de ação e reflexão, nesta última procurei mostrar a ideia errônea de que ensinar se aprende ensinando e, portanto, não é preciso preparar-se para ser professor. Contudo, este pensamento não possui sustentação, uma vez que a docência em todas as suas dimensões representa um desafio e exige um conjunto de conhecimentos para o seu exercício.

\section{Organização e planejamento da aula frente às contingências da sala de aula}

Dou início às análises destacando a organização das aulas frente às contingências da sala de aula. Quando perguntados sobre a forma como organizam a sua prática pedagógica, os depoimentos deixaram transparecer a pouca importância dada ao planejamento e a organização da aula:

"Bah (risos)... Nunca fiz um plano de aula! Nunca! De que forma que eu organizo? Eu pego o que eu tenho que dar hoje... Eu tento trazer a realidade do mercado de trabalho, ou seja, eu tenho uma programação prévia sobre o que eu vou falar, de que forma eu vou falar, quais são as estratégias que eu vou usar... Nada no papel eu confesso... É uma coisa que eu até tenho que me policiar, mas eu leio o que eu vou dar... Aí chego na aula e sinto o clima." (DÉBORA)

A organização e o planejamento de um processo tão complexo como a aula não podem resultar de um movimento mecânico e simplista. "A aula não pode ser pensada como um receituário ou uma ação improvisada em torno de um tema” (VEIGA, 2008, p. 268).

Interpreto pela fala de Débora que planejar a aula ainda é uma atividade pouco familiar em seu cotidiano pedagógico ao afirmar que nunca fez um plano de aula, que organiza os conteúdos no dia da sua aula. Vejamos outro depoimento:

"Eu te confesso que plano de aula eu nunca fiz! Eu me baseio no cronograma e na turma... Cheguei à aula comecei a ministrar o conteúdo e tipo... Não tá rolando eu já mudo.” (DÉBORA)

A organização da aula é marcada pela improvisação, não possuindo, a princípio, uma organização didática. Concordo com Veiga (2008) quando afirma que a importância do planejamento e da organização da aula está em 
evitar a improvisação das tarefas docentes. No contexto educativo, o planejamento tem como objetivo maior fornecer ferramentas à organização das ações da escola e do professor.

Também os professores se mostraram incomodados com a questão dos cronogramas das disciplinas e a forma como estes se apresentam e interferem no planejamento das aulas. Ainda sobre esta questão os professores mostraramse incomodados com o "engessamento do cronograma" e a necessidade de revê-lo e (re)adequá-lo à realidade e interesse de cada turma, de cada aluno:

“[...] aqui na escola o cronograma já vem pré-estabelecido [...] o que eu acho um pouco fechado de mais... Eu acho que o ideal seria a gente poder, cada professor, trazer do seu jeito, introduzir algumas coisas diferentes do que só aquilo que está focado ali no programa, mas eu sempre procuro organizar mesmo tendo esta rigidez de cronograma, de conteúdo, tentar voltar um pouco à realidade daquela turma, porque a gente tem aqui alunos de 17 a 60 anos, de realidades diferentes então eu procuro fazer isso, programar a aula para aquela realidade, tentar conhecer o aluno antes de a gente começar no primeiro dia de aula." (MADALENA)

Parece-me claro a preocupação dos professores quanto a sua aula e a forma como irão organizar e trabalhar didaticamente os conteúdos de suas disciplinas. Veiga (2008) ressalta que o objetivo principal da organização didática da aula é possibilitar ao professor um trabalho docente mais significativo e comprometido com a qualidade das atividades propostas. Para a autora a organização didática da aula representa "o produto de um movimento processual de reflexão e decisão, de comprometimento e criticidade" (VEIGA, 2008, p. 274).

O primeiro passo foi dado pelos próprios professores ao indagarem sobre a prática pedagógica, sobre a organização didática de suas aulas; questionando seu papel e sua responsabilidade no momento de organizar a aula, os professores acabam refletindo sobre o currículo e sobre as decisões no espaço da escola:

"Na realidade a gente não tem aqui na escola participação nesse currículo, uma vez só me chamaram para conversar sobre isso, mas não é uma coisa que a gente tenha envolvimento mais ativo nisso. Então acho que a não participação dos professores sobre o currículo da escola e nas práticas, cronogramas etc., [...] isso é ruim até para o crescimento da escola. Eu acho que o professor é a melhor pessoa para poder avaliar o que está sendo feito, o que tem que melhorar, porque é agente que está no dia a dia da sala de aula e não o pedagogo, não a direção da escola, então o professor tinha que estar envolvido no projeto político pedagógico da escola e nessa revisão e reavaliação dos currículos." (MADALENA)

Não obstante...

Educação Por Escrito, Porto Alegre, v. 7, n. 1, p. 74-87, jan.-jun. 2016 
"Nós tivemos muito pouca participação nessa construção do currículo, carga horária das disciplinas, etc. Eu acredito que deveria haver reuniões por parte de todos os professores para que a gente pudesse conversar a respeito do currículo, das cargas horárias, das ementas, dos conteúdos. Eu acho que falta um pouco disso né, então não acho que haja a participação." (DÉBORA)

Indagar e questionar, assim como fizeram Madalena e Débora em seus depoimentos, é uma condição do inacabamento humano; perguntar e questionar são formas de manifestar o ato curioso na busca de compreensão e desvelamento do mundo (VEIGA, 2008). As professoras mostraram, em suas falas, a insatisfação em relação a pouca participação na vida da escola, além da preocupação quanto a fragmentação do conhecimento no interior das disciplinas.

Demonstraram também consciência da complexidade do ato educativo e, por isso, buscam melhorá-lo, revendo os movimentos de reprodução de sua prática:

“Em algumas disciplinas é necessário alterar ou inverter alguns assuntos para que eles tenham uma coerência, para que eles tenham uma lógica, porque por vezes é necessário que isso seja feito de forma diferente dependendo da disciplina. Esta situação pré-estabelecida, por vezes, pouco a pouco, dependendo da turma é necessária ser modificada. Dependendo da turma é preciso ser feito. É importante que tu tenhas uma flexibilização isso porque a escola pode não autorizar completamente, mas indiretamente é necessário no que pesa alcançar o objetivo.” (SALOMÉ)

Outra inferência que faço ao analisar as falas dos professores é de que a escola parece estar inserida num contexto tradicional de educação, regido pelo paradigma dominante, no qual não há necessidade de compreender o todo, não havendo a oportunidade do diálogo entre as disciplinas do curso, muito menos a possibilidade de trabalhar e encontrar relações entre elas.

Para Simon (2010) a própria organização escolar favorece a cultura pedagógica que se concretiza por uma configuração fragmentada dos conhecimentos que ali transitam. Tal fato me pareceu claro na fala de Salomé quando afirmou que os conteúdos pré-estabelecidos do cronograma, por vezes, precisam ser modificados no momento de organizar sua aula, pois é necessário atentar para as necessidades formativas de seus alunos, no propósito de atingir os objetivos e interesses dos educandos.

Mas o êxito no alcance dos objetivos e interesses dos alunos depende da forma como o professor enfrenta as incertezas e a complexidade do mundo da prática. Veiga (2008, p. 272-273) destaca três aspectos da organização da aula que são significativos para o seu sucesso: 
a) Em primeiro lugar, a importância da relação professor-aluno como a ideia nuclear da concepção de docência. A docência existe para uma relação com os alunos, para agir com eles. É uma relação que tem o outro, no caso, o aluno, por princípio e fim. b) O segundo aspecto diz respeito à dimensão socializadora da aula, uma vez que os professores reconhecem a importância de envolver ativamente os alunos em seu processo de aprendizagem. c) O terceiro aspecto a ser considerado na organização da aula está relacionado às condições, muitas vezes adversas, a serem enfrentadas pelos professores, tais como, tamanho da turma, características dos alunos, falta de materiais e equipamentos adequados, tempo escasso, intensificação dos trabalhos acadêmicos, em virtude das exigências da produção científica, além dos 'percalços e contradições do mundo da prática.

Quando questionados sobre as dificuldades encontradas ao planejar as aulas salientam que o tempo é uma das barreiras encontradas:

“O tempo, porque muitas vezes, como eu não sou exclusivamente professora e, às vezes, eu dou aula nos três turnos, eu trabalho nos três turnos, falta tempo, tipo de poder chegar em casa estudar com mais calma e talvez preparar alguma coisa a mais ou diferente [...] Além do tempo, eu tive nas primeiras turmas que voltar, às vezes, em ensinamentos básicos da escola primária que eles não tiveram, que muitos fizeram o supletivo, a EJA, então não viram e eu não podia entrar com um conteúdo mais avançado tinha que primeiro voltar lá nas bases do conhecimento, da ciência, da biologia as vezes da química, da física para depois continuar." (SARA)

A maioria dos interlocutores concorda que o tempo é uma das dificuldades e dos desafios encontrados na organização da aula. Entretanto, se a organização e o planejamento da aula são um processo, então necessita de um tempo cronológico e pedagógico e, se este for aproveitado com qualidade, então podemos supor que quanto maior for a quantidade de tempo melhor serão os processos - ensinar, aprender, avaliar, interagir, socializar (VEIGA, 2008).

Vale registrar que o tempo pedagógico da aula é o tempo da produção de conhecimentos e de construção das relações interativas. É o tempo de estimular o desejo de aprender do aluno. "O tempo pedagógico é o tempo organizado para fortalecer a tríade relacional professor-aluno-conhecimento, para desenvolver as atividades didáticas relevantes de ensinar, aprender, pesquisar e avaliar" (VEIGA, 2008, p. 291).

Quando indagam sobre o tempo, é preciso ter claro que não se trata apenas do tempo cronológico, da quantidade de horas para a realização do seu trabalho, mas também, do tempo enquanto qualidade da sua ação docente (reflexões e ações nela contidas). 
Frente a tudo que foi discutido até o momento, uma pergunta se faz necessária: Qual o verdadeiro compromisso assumido pelo professor e responsabilidade no momento de organizar e planejar a sua aula?

Veiga (2008) ressalta que o ponto de partida para responder a estes questionamentos é considerar o conhecimento e a análise da realidade em que estão inseridos professores e alunos com o intuito de detectar as necessidades dos estudantes.

\section{Prática pedagógica como um processo de ação e reflexão}

À medida que se vai construindo a prática pedagógica, novos conhecimentos, novas experiências vão a ela se incorporando e se transformando em trabalho docente, ou seja, em experiência profissional. Este trabalho docente é mediado pelo agir pedagógico que se constrói e reconstrói com novos conhecimentos e novas experiências (TARDIF, 2008).

Neste contexto, a prática pedagógica, que é o agir docente no espaço escolar, depende não só dos conhecimentos formais, adquiridos nos cursos de formação, mas também depende das ações e reflexões que o professor faz do seu agir docente, das relações com seus alunos, de seus pares e da própria escola. É neste sentido que Tardif (2008) aponta os saberes escolares, os saberes pedagógicos e os saberes docentes e experiências como fenômenos que se misturam na atividade diária do professor.

Considero importante que o professor fundamente sua prática nos saberes da docência, os quais em diálogo com os desafios do cotidiano escolar sustentam e possibilitam o desenvolvimento da identidade de um profissional reflexivo, crítico, articulado a contextos mais amplos, considerando o ensino como uma prática social (GRILLO; GESSINGER, 2008).

Sobre os desafios do cotidiano enfrentados na escola técnica, destaco a fala de Maria em que reconhece a evolução do conhecimento e seu impacto sobre os processos de ensino e de aprendizagem. Posso inferir, ainda, pelo depoimento da entrevistada que a prática educativa se apresenta bastante complexa no ensino técnico e que frente a esta realidade as preocupações se manifestam na mesma proporção das transformações pelas quais a escola e a sociedade como um todo estão passando:

“A maior exigência é o teu aperfeiçoamento constante... E outra questão que é muito importante é ter que se inteirar também com a realidade da comunidade que tu está trabalhando, com a realidade dos alunos isso é muito importante para ter maior interação, maior entendimento [...] Os alunos de hoje eles têm muito mais sede pelo conhecimento, pelo saber, eles são muito mais questionadores, eles relacionam isso a todo o momento com as outras disciplinas, com o meio em que eles estão inseridos; acredito que os próprios professores hoje façam isso, antigamente os professores queriam passar os conteúdos específicos, prontos, e hoje todos os professores em todas as áreas eles querem estimular o pensar, o criar, ensinar a se posicionar." (MARIA)

Educação Por Escrito, Porto Alegre, v. 7, n. 1, p. 74-87, jan.-jun. 2016 
O relato acima demonstra consciência por parte da professora das contingências da sala de aula, por isso, busca melhorar o seu fazer pedagógico, exigindo dela mesma e, porque não dizer, dos próprios colegas, uma consciência reflexiva de si, uma postura mais aberta ao diálogo, ao novo, o respeito com os saberes trazidos previamente pelos alunos.

A prática pedagógica de muitos professores é caracterizada por situações imprevisíveis, incertas e conflitivas, não podendo ser resolvida unicamente pela aplicação de prescrições ou regras determinadas (GRILLO; GESSINGER, 2008).

Frente a este cenário, é exigida uma nova postura profissional do professor. A sua atividade necessita estar pautada na reflexão atenta sobre a situação vivenciada no confronto com a teoria e com as experiências vividas no contexto escolar, as quais, apesar de não se repetirem, servem de referência ao docente para que possa ir consolidando o seu conhecimento profissional.

O professor age reflexivamente, toma decisões, assumindo por meio da reflexão a sua ação como docente, analisando criticamente a sua prática pedagógica, seus erros e acertos no transcurso de sua aula. A este respeito, as professoras afirmam refletir sobre suas ações; também demonstram preocupação com o seu aluno, mostrando-se pessoas abertas que sabem refletir e dialogar:

"Eu sempre faço uma autoavaliação no final do semestre com os alunos [...] Eu pergunto sobre a disciplina... Aspectos que eles mais gostaram o que eles não gostaram referente aos conteúdos, se o professor, no caso, se eu fui clara, objetiva ou não [...] Isso é importante para o professor rever muitas coisas, porque a nossa profissão, não pode, não tem como tu seres uma pessoa engessada, tu tens que ser muito flexível, precisa entender, saber ceder a opiniões, tem que saber mudar também né, porque a gente bem ou mal está servindo, prestando um trabalho para as outras pessoas que vai ser fundamental na vida deles." (MARIA)

Para outra professora suas ações, seus erros e acertos permitem...

"Refletir o que aconteceu no dia de aula, aquilo que poderia ser melhor. Existem dias em que noto que os alunos estão mais dispersos, tem dias que os alunos não estão tão concentrados [...] os motivos que a aula não teve o andamento que estava se buscando. A gente observa muito por vezes que o indivíduo ele está pouco concentrado, às vezes preocupado com outras questões pessoais ou até mesmo com outras disciplinas e como mostrar isso de forma mais interessante para o aluno." (SALOMÉ).

As falas das professoras me permitem afirmar que refletir sobre a prática é fundamental na vida do docente, pois "é pensando criticamente a prática de hoje ou de ontem que se pode melhorar a próxima prática" (FREIRE, 1996, p. 44). 
"Eu sempre estou procurando me avaliar e gosto que eles me avaliem... Não tenho medo de perguntar se eles estão gostando da aula, se estão aprendendo, pois não adianta dá uma aula divertida e eles saírem dali sem ter entrado nada na cabeça.” (EVA)

É refletindo criticamente sobre a prática que as professoras vão dando conta da necessidade de repensar o seu trabalho docente, assumindo, assim, o ato reflexivo, como um processo metodológico e instrumental promotor de debates sobre situações problemáticas que podem vir a ser vivenciadas pelos professores no contexto escolar (GRILLO; GESSINGER, 2008). Além disso, as professoras possuem consciência da importância do diálogo, das trocas de experiências. Contudo, manifestam a necessidade de haver, por parte da escola, encontros que realmente pudessem proporcionar aos docentes a possibilidade de discutir e repensar a prática...

“Acho que esta questão da reunião dos professores eu acho que é importantíssima para eu ouvir os meus colegas, ouvir quais são as dificuldades que eles têm... Como é que é determinada turma... Porque cada turma se mostra de uma forma diferente. Então se tivesse mais reuniões entre professores, cursos, treinamentos, uma formação continuada [...].” (DÉBORA)

Cunha (1998, p. 109) afirma que:

I O trabalho coletivo reforça a possibilidade de êxito das iniciativas individuais através da possibilidade de partilha, da troca de experiência, da reflexão conjunta e realimenta a disposição do professor que se dispõe a fazer ruptura com a prática pedagógica dominante.

Nesta perspectiva, posso identificar um elemento significativo e presente nas manifestações das professoras: $O$ fato de que elas querem mudar sua ação, mas muitas vezes não conseguem desenvolver caminhos metodológicos para a renovação de sua prática - seja porque não romperam com uma forma de educar estruturada pelo paradigma tradicional de educação, seja porque não viram a escola como um espaço de formação que possibilite a reforma de sua ação.

Certo é que os saberes e fazeres dos professores se constituem a partir da reflexão na e sobre a prática. São inseparáveis, produzidos na ação e (re)inventados a partir de uma determinada prática social da educação. Dessa forma, por tudo que foi apresentado, as reflexões expostas nos depoimentos das professoras me permitem assumir o pensamento complexo no contexto da educação. 


\section{Considerações finais}

Aprendi muito com esta pesquisa e acredito que ela tenha servido para que eu pudesse refletir sobre o ensino e, principalmente, sobre a escola técnica. Num primeiro momento pensei que encontraria professores acomodados com as situações impostas pelo cotidiano escolar; mas estava enganado. Conheci professores preocupados com a formação de seus alunos, professores dedicados ao extremo, professores comprometidos com a escola e com o ato educativo.

Frente a esta realidade, a prática pedagógica dos professores se apresenta bastante complexa, e as preocupações manifestadas em suas falas perpassam justamente as constantes e ininterruptas transformações pelas quais o ensino está passando.

Cada professora entrevistada expressou, a seu modo, a convicção de que é necessário haver a mudança, entretanto parece-me que os docentes não se percebem como agentes da transformação. Percebo pelas falas das professoras entrevistadas que a maioria delas em sua prática pedagógica parecem não saber como agir e lidar com as contingências da sala de aula.

Com relação à organização da aula esta é marcada pela improvisação, não possuindo, a princípio, uma organização didática. Paradoxalmente, os professores mostraram-se incomodados com a questão dos cronogramas das disciplinas e a forma como estes se apresentam e interferem no planejamento das aulas.

Observo que os professores indagam e refletem sobre a prática pedagógica, sobre a organização didática de suas aulas, questionando seu papel e a sua responsabilidade no momento de organizar a sua aula, assim como a sua participação sobre o currículo e sobre as decisões no espaço da escola.

As professoras mostraram, em suas falas, a insatisfação em relação a pouca participação na vida da escola, além da preocupação quanto à fragmentação do conhecimento no interior das disciplinas. Demonstraram também consciência da complexidade do ato educativo e, por isso, buscam melhorá-lo. A maioria das entrevistadas concorda que o tempo é uma das dificuldades e desafios encontrados na organização da aula.

Os docentes possuem consciência da importância do diálogo, das trocas de experiências. Contudo, manifestam a necessidade de haver, por parte da escola, encontros que realmente pudessem proporcionar aos docentes a possibilidade de discutir a prática.

Em suma, parece-me que o primeiro passo já foi dado pelos professores ao reconhecerem a necessidade de mudanças. Mesmo que esta referida mudança (paradigmática) não tenha sido dita de forma explícita pelos docentes há uma clara percepção por parte deles de que o cenário atual vem exigindo uma (re)construção da profissionalidade do professor e uma (re)adequação do fazer pedagógico para o atendimento das demandas trazidas pelos alunos em sala de aula. 


\section{Referências}

ANDRÉ, Marli. Etnografia da prática escolar. Campinas: Papirus, 1998. 128 p.

BECKER, Howard. Métodos de pesquisa em ciências sociais. 3. ed. São Paulo: Hucitec, 1997. 178 p.

CONTRERAS DOMINGO, José. Ser y saber en la formación didáctica del profesorado. Revista Interuniversitaria de Formación del profesorado, Zaragoza, n. 68, v. 2, p. 61-81, ago. 2010.

CUNHA, Maria Isabel. O professor universitário na transição de paradigmas. Araraquara: JM Editora, 1998.

FERREIRA, Angelita da Rocha Oliveira. Os professores da educação profissional: sujeitos (re)inventados pela docência. 2010. 138f. Dissertação (Mestrado em Educação) - Pontifícia Universidade Católica do Rio Grande do Sul, 2010.

FREIRE, Paulo. Pedagogia da autonomia: saberes necessários à prática educativa. Rio de Janeiro: Paz e Terra, 1996. 54 p.

Conscientização, teoria e prática da libertação: uma introdução ao pensamento de Paulo Freire. São Paulo: Moraes, 1980.

GARCÍA, Carlos Marcelo. Formação de professores: para uma mudança educativa. Porto: Porto Editora, 1999. 271 p.

GOLDIM, Jose Roberto. Manual de Iniciação Científica. Porto Alegre: Da Casa Editora, 1997. 199 p.

GRILLO, Marlene Correro; GESSINGER, Rosana Maria. Constituição da identidade profissional, saberes docentes e prática reflexiva. In: GRILLO, Marlene et al. (Orgs.). A gestão da aula universitária na PUCRS. Porto Alegre: EDIPUCRS, 2008. p. $35-42$.

GRILLO, Marlene. O professor e a docência: o encontro com o aluno. In: ENRICONE, Délcia (Org.). Ser professor. Porto Alegre: EDIPUCRS, 2002. p. 73-90.

LÜDKE, Menga; ANDRÉ, Marli. Pesquisa em Educação: abordagens qualitativas. São Paulo: EPU, 1986. 99 p.

MINAYO, Maria Cecília de Souza (Org.) et al. Pesquisa social: teoria, método e criatividade. Rio de Janeiro: Vozes, 1994.80 p.

MORAES, Roque. Uma tempestade de luz: a compreensão possibilitada pela análise textual discursiva. Ciência \& Educação, UNESP: v. 9, n. 2, p. 191-211, 2003.

NÓVOA, António. Os professores e as histórias da sua vida. In:

Vidas de Professores. Porto: Porto Editora, 1992. p. 11-30.

PÉREZ GOMÉZ, Angel. Nuevas exigencias y escenarios para la profesión docente en la era de la información y de la incertidumbre. Revista Interuniversitaria de Formación del Profesorado, Zaragoza, v. 24, n. 68, p. 17-36, ago. 2010.

SANTOS, Antonio Raimundo. Metodologia Científica: a construção do conhecimento. Rio de Janeiro: DP\&A Editora, 1999. 139p. SOUSA SANTOS, Boaventura. Um discurso sobre as ciências. Porto: Edições Afrontamento, 2009. 92 p.

SIMON, Marinice Souza. Professores e paradigmas em transição: saberes, rupturas, limites e desafios. 2010. 103f. Dissertação (Mestrado em Educação) - Pontifícia Universidade Católica do Rio Grande do Sul, 2010.

TARDIF, Maurice. Saberes docentes e formação profissional. Petrópolis: Vozes, 2008. 325 p. 
VEIGA, Ilma Passos de Alencastro. Organização didática da aula: um projeto colaborativo de ação imediata. In: Gênese, dimensões, princípios e práticas. Campinas: Papirus, 2008. p. 267-298.

Recebido em: janeiro/2016

Aceito em: maio/2016

\section{Endereço para correspondência:}

José Augusto Florentino

Rua 24 de Maio, 141 - Centro

Cep: 95520-000 - Osório, RS, Brasil

<jose.a.florentino@gmail.com> 